\title{
Esophageal cancer awareness in Bomet district, Kenya
}

\author{
*Duron $\mathrm{V}^{2}$, Bii J ${ }^{1}$, Mutai $\mathrm{R}^{1}$, Ngetich $\mathrm{J}^{1}$, Harrington $\mathrm{D}^{2}$, Parker $\mathrm{R}^{2}$, White $\mathrm{R}^{1}$
}

1. Tenwek Hospital Community Health Center, Bomet, Kenya

2. Department of Surgery, Alpert Medical School of Brown University, Rhode Island Hospital

\begin{abstract}
Background: Esophageal cancer is the most common malignancy in Western Kenya and patients present with advanced disease.

Objective: To determine baseline level of knowledge of esophageal cancer in Bomet District in order to develop targeted and effective educational classes.

Methods: A questionnaire with twelve questions testing knowledge about esophageal cancer and eight questions aimed at determining barriers to healthcare was conducted out of Tenwek Hospital from June to July 2010.

Results: Eighty-one questionnaires were completed. 33\% thought that cancer is a virus and 35\% thought that it is contagious. $47 \%$ did not think that family history is a risk factor. $79 \%$ accurately claimed dysphagia as the most common symptom for esophageal cancer. $40 \%$ thought that herbal therapy is the optimal treatment for esophageal cancer. Cost and fear of diagnosis were cited as the most significant barriers to healthcare. Most participants had a monthly income of less than 3000 Kenyan schillings (37.5 US dollars); for 37\% of participants, the cost of transport to the hospital represented a third of their monthly income.

Conclusion: The questionnaire provided population-specific information on cancer knowledge and aided in targeting barriers to healthcare access. These factors will be incorporated into the cancer education outreach program of Tenwek Hospital.
\end{abstract}

African Health Sciences 2013; 13(1): 122 - 128 http://dx.doi.org/10.4314/ahs.v13i1.17

\section{Introduction}

Cancer is frequently overlooked as a significant contributor to the global burden of disease, despite being responsible for $20 \%$ of the 11 million annual deaths in developed countries and 13\% of the 22 million annual deaths in developing countries ${ }^{1}$. In fact, once an individual has survived the first five years of life, cancer becomes one of the major causes of death. Furthermore, the World Health Organization predicts there will be 16 million new cancer cases each year in 2020 with $70 \%$ occurring within the developing world ${ }^{2}$. Given this significant burden to public health, there has been recent interest in expanding cancer prevention, diagnosis, treatment, and palliation ${ }^{3}$.

Esophageal cancer is the $9^{\text {th }}$ most common cancer in the world, and the $5^{\text {th }}$ most common cancer

\author{
*Corresponding author: \\ Vincent Duron \\ General Surgery Resident \\ Alpert Medical School of Brown University \\ Department of Surgery, Rhode Island Hospital \\ 573 Eddy St, APC 4 \\ Providence, RI 02903 \\ Tel: $585-368-8391$ \\ Email: vincent_duron@yahoo.com
}

in developing countries, with approximately 300,000 newly diagnosed cases each year. A unique epidemiological feature of esophageal cancer is its very uneven geographic distribution, with high incidence found within sharply demarcated geographic confines. These hot-spots include areas in northern Iran, Kazakhstan, South Africa, and northern China, where annual incidence can exceed 200 per 100,000 per year, and over $20 \%$ of all deaths can be attributed to esophageal cancer alone 4 . Most studies of esophageal cancer in Africa have come from South Africa, where rates of this cancer have been reported to be very high. Few reports have examined the occurrence of esophageal cancer in Central and Eastern Africa.

The first case series looking at esophageal cancer in Kenya by Ahmed and Cook in 1969 found that in certain regions of Central and Western Kenya, esophageal cancer ranked as the first or second most common cancer ${ }^{5}$. Another case series by Gatei et al in 1978 also found a relatively high proportion of cases in individuals from Western Kenya ${ }^{6}$. A more recent and extensive study carried out at the Moi Teaching and Referral Hospital in the North Rift Valley of Western Kenya retrospectively examined the charts of all patients diagnosed with cancer 
between 1994 and $2001(n=3400)$. They found that esophageal cancer was the most common malignancy in men and the third most common in females, and that it represented $13.8 \%(n=468)$ of all cancers. Furthermore, a significant percentage of cases $(10 \%)$ occurred in young patients less than 40 years of age $\mathrm{e}^{7}$.

Similarly, a recent retrospective study originating from the hospital where this study was conducted, Tenwek Hospital of Bomet District in Western Kenya, also concluded that esophageal cancer was the most common malignancy. Of the 2643 patients presenting to this hospital with cancer from 1999 to 2007, 35\% had esophageal cancer. This was the most common cancer in both men and women. Again, a significant number of young patients (under the age of 30) presented with esophageal cancer; in this case $6 \%$. The youngest patient was 14 years old. As in prior studies, they found that most patients presented with cancer only after they started experiencing symptoms, which is usually indicative of advanced disease and associated with only a $25 \%$ five-year survival rate. In fact most cancers at time of presentation were too advanced for curative resection and were amenable only to palliative treatment such as esophageal stenting ${ }^{8,9}$

As mentioned above, esophageal cancer is a significant contributor to mortality in Western Kenya. It is the most common cancer in the Bomet region, and has been shown to also affect the very young. Unfortunately, knowledge of cancer has been shown to be poor in Kenya and other African countries $^{10,11,12}$. Due to a lack of structured health education programs, it is hypothesized that knowledge of cancer and its associated signs, symptoms, and risk factors is also poor in this region of Kenya. The purpose of this pilot study was to determine the level of knowledge of esophageal cancer in the target community, Bomet district, and determine what barriers to accessing healthcare are most significant in preventing people from participating in available cancer screening programs.

\section{Methods}

This study received full IRB approval from both Brown University, with whom the authors are university-affiliated, and Tenwek Hospital, where the research was conducted.

A questionnaire was developed with the help of local staff members that tested knowledge about esophageal cancer. Focus groups were held to ensure that the questionnaire was culturally appropriate. One focus group was undertaken with the nine members of the Tenwek Hospital Community Outreach Center, including the director of this department. This session focused specifically on establishing questions that would accurately quantify the knowledge basis of the community members and were culturally acceptable. Additional focus groups were completed with community leaders of the communities studied. These were undertaken on an informal basis during outreach trips prior to the beginning of the study to ensure acceptance of the study and to better determine the interests of the community members themselves.

Additional questions probing what factors hinder access to healthcare were also included. Finally several slots were allotted to documentation of demographic data. Overall, there were 12 questions on cancer knowledge, 8 on barriers to healthcare, and 13 documenting demographics. The questionnaire was in multiple choice question format.

Over the course of five weeks from June to July of 2010, 81 questionnaires were completed in various communities surrounding Tenwek Hospital. All communities were located in Bomet district in Western Kenya, ranging from 5 to $20 \mathrm{~km}$ away from the hospital. The questionnaires were handed out during community outreach trips run by the Tenwek Hospital Community Center. The purpose of these trips was varied, ranging from distribution of child vaccinations to maternal health lessons to water filter construction and development. Overall, 83 individuals accepted to participate in the study, however two individuals did not complete the study, one because of loss of interest and the other because of time constraints. The two individuals who did not complete the questionnaire stated that they had lost interest in the study and did not want to. As the literacy rate in this area is low, and most people do not speak English, $86 \%$ of the questionnaires were conducted in Kipsigis, the local language, and $95 \%$ were completed in oral form. Local staff members assisted in translating the questionnaires. The questionnaires were conducted by the authors or by local staff members of the Tenwek Hospital Community Center, all of whom are trained healthcare professionals. No personal identifiers were used at any point during the study.

\section{Results}

In terms of demographic data, of the 81 individuals surveyed, $67 \%$ were female and $33 \%$ were male. Age ranged from 19 to 81 years. Forty-two percent 
of participants had completed Standard 8 (equivalent to completion of primary school in the United States), 17\% had completed Form 4 (equivalent to completion of secondary school) and $4 \%$ had continued on to technical training. Most of the participants $(72 \%)$ were farmers. Other commonly encountered professions were tailors, taxi drivers, shopkeepers, and truck drivers. Only 11\% reported ever having smoked and 15\% reported consuming alcohol. Eleven percent of participants had a family history of cancer, with $9 \%$ having a family history of esophageal cancer. Few participants (4\%) had previously undergone an upper endoscopy, most commonly for heartburn and gastro-esophageal reflux symptoms. The interview was conducted in Kipsigis in $86 \%$ of cases, Swahili in 6\%, and English in $7 \%$, and was done in oral form in $95 \%$ (table 1 ).

\section{Table 1: Demographic data}

\begin{tabular}{|c|c|c|}
\hline & No. & $(\%)$ \\
\hline \multicolumn{3}{|l|}{ Gender } \\
\hline Male & 27 & 33 \\
\hline Female & 54 & 67 \\
\hline Age & $19-81$ years & \\
\hline \multicolumn{3}{|l|}{ Education } \\
\hline Standard 8 & 34 & 42 \\
\hline Form 4 & 14 & 17 \\
\hline Technical/University & 3 & 4 \\
\hline \multicolumn{3}{|l|}{ Employment } \\
\hline Farmer & 58 & 72 \\
\hline \multicolumn{3}{|l|}{ Smoking } \\
\hline Yes & 9 & 11 \\
\hline \multicolumn{3}{|l|}{ Drinking } \\
\hline Yes & 12 & 15 \\
\hline \multicolumn{3}{|l|}{ Family History } \\
\hline Cancer & 9 & 11 \\
\hline Esophageal cancer & 7 & 9 \\
\hline \multicolumn{3}{|c|}{ Ever had a colonoscopy? } \\
\hline Yes & 3 & 4 \\
\hline \multicolumn{3}{|l|}{ Interview Language } \\
\hline Kipsigis & 70 & 86 \\
\hline Swahili & 5 & 6 \\
\hline English & 6 & 7 \\
\hline \multicolumn{3}{|c|}{ Method of interview administration } \\
\hline Oral & 77 & 95 \\
\hline Written & 4 & 5 \\
\hline
\end{tabular}

Results from the questions on cancer knowledge were as follows: $57 \%$ of participants accurately answered that cancer is an abnormal growth of cells, however 33\% thought that cancer is a virus, and 35\% thought that cancer is contagious. Most participants
$(86 \%)$ did answer that cancer can be cured if detected early, and $62 \%$ confirmed that there are things that you can do to avoid getting certain cancers. Knowledge about cancer prevalence was relatively good. The most common cancers in this region are esophagus, stomach, prostate and colorectal in that order; $36 \%$ of participants thought esophageal cancer is the most common and $40 \%$ thought stomach cancer is the most common (table 2).

In terms of risk factors, $30 \%$ thought that smoking tobacco was the only risk factor, $11 \%$ alcohol only, $12 \%$ family history only, and $41 \%$ determined that all three were risk factors. So $47 \%$ did not think that family history is a risk factor and $48 \%$ did not think that alcohol is a risk factor. Most participants $(93 \%)$ were not aware that screening endoscopy for esophageal cancer is free at Tenwek Hospital. Most participants (79\%) accurately stated that difficulty swallowing is the most common symptom of esophageal cancer. In terms of cancer treatment, $40 \%$ thought that herbal therapy was the treatment of choice, while $49 \%$ said surgery. Most were aware of the severity and poor prognosis of the disease: $61 \%$ affirmed that people die from this cancer, and almost half (47\%) stated that death most often occurred within 5 years (table 3 ).

Eight questions assessed barriers to healthcare. The most frequently stated reasons for not accessing healthcare were cost $(33 \%)$ and fear of diagnosis $(29 \%)$. Most participants $(70 \%)$ had to travel at least $10 \mathrm{~km}$ to get to the hospital. Most took public transport (54\%). For most, the cost of transport alone represented a significant portion of their monthly income. Most participants (60\%) had a monthly income of less than 3000 Kenyan schillings (37.5 US dollars) and for 34\% of participants, the cost of transport to the hospital represented $1000 \mathrm{KSh}$ (12.5 USD). For 37\%, that amount represents a third of their monthly salary. When participants were asked to propose other reasons that prevent them from seeing a physician, most reiterated that financial constraints were a significant barrier (table 4). 
Table 2: Cancer knowledge

\begin{tabular}{|c|c|c|c|}
\hline Topic Assessed & Participant response & No. & Percentage $(\%)$ \\
\hline \multirow[t]{5}{*}{ Definition of cancer } & Disease of old age & 2 & 3 \\
\hline & Abnormal growth of cells & 46 & 57 \\
\hline & Virus & 27 & 33 \\
\hline & $\begin{array}{l}\text { Curse that is placed on one } \\
\text { person from another }\end{array}$ & 1 & 1 \\
\hline & No answer & 5 & 6 \\
\hline \multirow[t]{3}{*}{ Early cancer detection improves cure rate } & Yes & 70 & 86 \\
\hline & No & 10 & 12 \\
\hline & No answer & 1 & 1 \\
\hline \multirow[t]{2}{*}{ Prevention of cancer is possible } & Yes & 50 & 62 \\
\hline & No & 31 & 38 \\
\hline \multirow[t]{3}{*}{ Cancer is contagious } & Yes & 28 & 35 \\
\hline & No & 49 & 61 \\
\hline & No answer & 3 & 4 \\
\hline Most common type of cancer in the South- & Esophagus & 29 & 36 \\
\hline \multirow[t]{7}{*}{ Rift Region of Kenya } & Stomach & 32 & 40 \\
\hline & Cervix & 2 & 2 \\
\hline & Prostate & 0 & 0 \\
\hline & Breast & 8 & 10 \\
\hline & Colon & 5 & 6 \\
\hline & $\begin{array}{l}\text { "Leg" (as proposed } \\
\text { by interviewee) }\end{array}$ & 4 & 5 \\
\hline & No answer & 1 & 1 \\
\hline
\end{tabular}

Table 3: Esophageal cancer knowledge

\begin{tabular}{|c|c|c|c|}
\hline \multirow{2}{*}{$\begin{array}{l}\text { Topic Assessed } \\
\text { Risk factors for esophageal cancer }\end{array}$} & \multirow{2}{*}{$\begin{array}{l}\text { Participant response } \\
\text { Smoking tobacco }\end{array}$} & \multicolumn{2}{|c|}{ No. $(\%)$} \\
\hline & & 24 & 30 \\
\hline & Heavy alcohol use & 9 & 11 \\
\hline & Family history & 10 & 12 \\
\hline & All of the above & 33 & 41 \\
\hline & No answer & 3 & 4 \\
\hline \multirow{5}{*}{$\begin{array}{l}\text { Cost of screening for esophageal cancer at } \\
\text { Tenwek Hospital }\end{array}$} & $10,000 \mathrm{KSh}$ & 23 & 28 \\
\hline & $1,000 \mathrm{KSh}$ & 35 & 43 \\
\hline & $100 \mathrm{KSh}$ & 8 & 10 \\
\hline & $0 \mathrm{KSh}$ & 7 & 9 \\
\hline & No answer & 8 & 10 \\
\hline \multirow[t]{5}{*}{ Symptoms associated with esophageal cancer } & Headache & 1 & 1 \\
\hline & Fever & 2 & 2 \\
\hline & Difficulty swallowing & 64 & 79 \\
\hline & Cough & 11 & 14 \\
\hline & No answer & 3 & 4 \\
\hline \multirow[t]{4}{*}{ Treatment options for esophageal cancer } & Herbal therapy & 32 & 40 \\
\hline & Surgery & 40 & 49 \\
\hline & Observation & 4 & 5 \\
\hline & No cure ever & 5 & 6 \\
\hline Treatment options available at Tenwek & Endoscopy & 19 & 23 \\
\hline \multirow[t]{3}{*}{ Hospital for esophageal cancer } & Stent & 16 & 20 \\
\hline & Surgery & 24 & 30 \\
\hline & All of the above & 16 & 20 \\
\hline
\end{tabular}

African Health Sciences Vol 13 Issue 1 March 2013 


\begin{tabular}{llll}
\hline Topic Assessed & Participant response & No. & $\mathbf{( \% )}$ \\
& None of the above & 1 & 1 \\
& No answer & 5 & 6 \\
Natural history of esophageal cancer & He/She will get better soon 3 & 4 \\
& After a long time with pain & 14 & 17 \\
& and suffering he/she will get better \\
& Nothing will happen to him 1 & 1 \\
& /her & & \\
& He/She will die & 61 & 75 \\
& No answer & 2 & 2 \\
Life expectancy of individuals with symptomatic & Less than 5 years & 38 & 47 \\
& esophageal cancer & & \\
& 5-10 years & 17 & 21 \\
& 10-20 years & 9 & 11 \\
As long as they would if & 14 & 17 \\
they didn't have cancer & & \\
\hline No answer & 3 & 4
\end{tabular}

Table 4: Barriers to healthcare

\begin{tabular}{|c|c|c|c|}
\hline Topics Assessed & Participant response & No. & $(\%)$ \\
\hline Most significant barrier to accessing & Cost & 29 & 33 \\
\hline \multirow{6}{*}{ healthcare } & Religion & 6 & 7 \\
\hline & Cultural rules & 6 & 7 \\
\hline & Transport & 3 & 3 \\
\hline & Fear of diagnosis & 25 & 29 \\
\hline & Fear of treatment (surgery) & 16 & 18 \\
\hline & No answer & 2 & 2 \\
\hline Distance participant lives from & Less than 5 kilometer $(\mathrm{km})$ & 11 & 14 \\
\hline \multirow[t]{3}{*}{ hospital } & $5-10 \mathrm{~km}$ & 14 & 17 \\
\hline & $10-20 \mathrm{~km}$ & 24 & 30 \\
\hline & More than $20 \mathrm{~km}$ & 32 & 40 \\
\hline \multirow{5}{*}{$\begin{array}{l}\text { Mode of transport used to travel } \\
\text { to hospital }\end{array}$} & On foot & 10 & 12 \\
\hline & Public transport & 44 & 54 \\
\hline & Private car & 21 & 36 \\
\hline & No transport option & 3 & 4 \\
\hline & No answer & 3 & 4 \\
\hline \multirow[t]{5}{*}{ Cost of transport to hospital } & $10,000 \mathrm{KSh}$ & 2 & 2 \\
\hline & $1,000 \mathrm{KSh}$ & 28 & 34 \\
\hline & $100 \mathrm{KSh}$ & 38 & 47 \\
\hline & $0 \mathrm{KSh}$ & 7 & 9 \\
\hline & No answer & 5 & 15 \\
\hline \multirow[t]{5}{*}{ Monthly income } & More than $30,000 \mathrm{KSh}$ & 0 & 0 \\
\hline & $6,000-30,000 \mathrm{KSh}$ & 2 & 2 \\
\hline & $3,000-6,000 \mathrm{KSh}$ & 10 & 12 \\
\hline & Less than $3,000 \mathrm{KSh}$ & 49 & 60 \\
\hline & No answer & 15 & 19 \\
\hline \multirow[t]{4}{*}{ Healthcare provider used } & Health clinic & 71 & 88 \\
\hline & Traditional healer & 3 & 4 \\
\hline & Family member or friend & 3 & 4 \\
\hline & No healthcare provider & 2 & 2 \\
\hline 126 & No answer & $\underset{\text { irican }}{2}$ & 2 Scic \\
\hline
\end{tabular}




\section{Discussion}

Esophageal cancer is the most common malignancy diagnosed in Western Kenya. Our study used a questionnaire to quantify the knowledge base that Kenyans from this region have on esophageal cancer and the factors that influence their access to care. Overall, the study participants were very knowledgeable about the incidence of esophageal cancer, its prognosis, and the associated risk factors and symptoms. However, they also exhibited some considerable knowledge gaps that may affect how they approach screening and treatment of this condition. Cost of transport was a significant barrier to their access to care.

The questionnaire revealed that Kenyans of the Bomet district have a relatively good knowledge base about esophageal cancer, yet certain important gaps and serious misconceptions do exist. They know that esophageal cancer is common in their area and understand the gravity of cancer and the poor prognosis that esophageal cancer in particular holds. Yet the fact that a significant portion of individuals think that esophageal cancer is a virus $(33 \%)$ and is contagious $(37 \%)$ is problematic. Unwanted consequences of this misconception include delay in diagnosis from fear of alienation from the community, as is seen with a diagnosis of HIV/AIDS. Conversely, they may not associate with and assist those suspected of having cancer from fear of being infected themselves. Finally, this misconception may lead individuals to belittle the gravity of their illness, if they think it is just an infectious disease that can be treated with antibiotics.

With so much government and media emphasis on infectious diseases such as tuberculosis, malaria and HIV/AIDS, it is no surprise that many defined cancer, with its poor prognosis, as a virus. Also, to be clear, although some viruses may lead to dysplastic changes that then cause cancer, this relationship is one of causality and certainly not of equivalence, as was inferred by the first question, and so it is wrong to assume that cancer is a virus. It is important to differentiate these two disease processes because one is usually fast-acting, with acute symptoms, such as fever, rash, or pain, while the other is accompanied by more subtle signs and symptoms, such as weight loss or anemia. Additionally with the revelation of this misconception, a simple intervention is to now affirm the fact that esophageal cancer is not contagious to each newly diagnosed patient in the caregiver's explanation of the disease process.

One interesting finding is the fact that if an individual in the community had a certain type of cancer, then most of those interviewed depicted this cancer as being the most common cancer in the region. For example, a known individual in one of the communities we visited suffered from "cancer of the leg." The majority of those interviewed from that community stated that "cancer of the leg" was the most common cancer in Kenya. Further education on cancer prevalence should target such easily construed misconceptions.

The fact that $79 \%$ of participants associated the correct symptom with esophageal cancer is a very encouraging first step. Yet they are unable to complete the subsequent step toward diagnosis and treatment. Most importantly, they are constrained by financial means. Just the cost of transport to the hospital is a significant barrier - frequently representing a third of their monthly income. However, they are unaware of services that are already in place and available to them at no charge. Tenwek Hospital offers free screening endoscopies for esophageal cancer, yet only $7 \%$ of those interviewed were aware of this service.

There were a few limitations to this pilot study. Literacy rates are low in this rural region of Kenya, as they are in the majority of the country, and so, although they are representative of Kenyan level of education in general, there may still have been some confusion about the questions asked. Also, the majority of the questions were translated from English to Kipsigis, and some understanding of the question may have been lost in the translation. The surveys were conducted at community health outreach programs thus there exists a potential bias for interviewees who are already receptive to health education and awareness. If such a bias held true, this suggests that other community members may be less knowledgeable. Finally, a sample size of 81 patients brings forth the question of power of the study. The purpose of this study, however, was to be a springboard for developing educational projects, which we believe was accomplished.

Although multiple studies have examined individuals' knowledge base of esophageal cancer in Europe and the United States, this is the first study looking at this issue in an African country. There have been a number of studies investigating awareness of other malignancies, such as cervical and breast cancer in African women, but none specifically looking at esophageal cancer ${ }^{10,11,12}$. As esophageal cancer is the most common malignancy in Western Kenya, we feel that this is an important pilot study to use in the development of focused community outreach programs that may assist in the earlier detection and treatment of this disease. 
A cancer outreach team is already in the development phase at Tenwek Hospital. The knowledge gaps elicited from our questionnaire will be better targeted with the curriculum used on these trips. The World Health Organization (WHO) publishes modules on cancer education and prevention that will be used to improve upon the pre-existing class curriculum.

Lack of adequate transport has often been cited as a significant barrier to access to healthcare in developing countries ${ }^{15,16,17}$. For this reason, the outreach projects already stemming from the Tenwek Community Center have been so successful. Adding cancer education to these trips will be vital in educating people of the community. A mobile endoscopy unit may ideally complement the current outreach program. After analysis of the study's results and in-depth discussion with local healthcare providers and hospital administrators, a better understanding of the barriers to care and the feasibility of such programs will be determined and, if appropriate, the development of a mobile endoscopy unit may be undertaken.

\section{Conclusion}

The questionnaire provided population-specific information on cancer knowledge and aided in targeting barriers to healthcare access. These factors will be incorporated into the cancer education outreach program of Tenwek Hospital.

\section{References}

1. Boffetta P, Parkin DM (1994) Cancer in developing countries. CA Cancer J Clinic 44(2): 81-90.

2. Lingwood RJ, Boyle P, Milburn A, Ngoma T, Arbuthnott J, McCaffrey R, et al (2008) The challenge of cancer control in Africa. Nat Rev Cancer 8:398-403.

3. Farmer P, Frenk J, Knaul FM, Shulman LN, Alleyne G, Armstrong L, et al (2010) Expansion of cancer care and control in countries of low and middle income: a call to action. The Lancet 376(9747):1186-93.

4. Parkin DM, Pisani P, Ferlay J. Estimates of the worldwide incidence of eighteen major cancers in 1985 (1993) Int J Cancer 54: 594-606.

5. Ahmed N, Cook P (1969) The incidence of cancer of the esophagus in West Kenya. $\mathrm{Br} \mathrm{J}$ Cancer 23:302-12.

6. Gatei DG, Odhiambo PA, Orinda, Muruka FJ, WasunnaA (1978) A retrospective study of carcinoma of the oesophagus in Kenya. Cancer Res 38(2):303-07.
7. Wakhisi J, Patel K, Buziba N, Rotich J (2005) Esophageal cancer in north rift valley of Western Kenya. African Health Sciences 5(2): 157-63.

8. Parker RK, Dawsey SM, Abnet CC, White RE (2010) Frequent occurrence of esophageal cancer in young people in western Kenya. Dis Esophagus 1;23(2):128-35.

9. White RE, Parker RK, Fitzwater J, Kasepoi Z, Topazian M (2010) Stents as sole therapy for oesophageal cancer: a prospective analysis of outcomes after placement. Lancet Oncol 10(3):240-246.

10. Osime OC, Okojie O, Aigbekaen ET, Aigbekaen IJ (2008) Knowledge attitude and practice about breast cancer among civil servants in Benin City, Nigeria. Ann Afr Med 7(4):192-7.

11. Gichangi P, Estambale B, Bwayo J, Rogo K, Ojwang S, Opiyo A, et al (2003) Knowledge and practice about cervical cancer and Pap smear testing among patients at Kenyatta National Hospital, Nairobi, Kenya. Int J Gynecol Cancer.13(6):827-33.

12. Aderounmu AO, Egbewale BE, Ojofeitimi EO, Fadiora SO, Oguntola AS, Asekun-Olarinmoye EO, et al (2006) Knowledge, attitudes and practices of the educated and non-educated women to cancer of the breast in semi-urban and rural areas of SouthWest, Nigeria. Niger Postgrad Med J 13(3):182-8.

13. FitzGerald SC, Al Sahaf M, Furlong H, Pennycooke K, Healy C, Walsh TN. Lack of awareness of oesophageal carcinoma among the public in Ireland. Ir J Med Sci. 2008 Jun;177(2):151-4.

14. Tentzeris V, Lake B, Cherian T, Milligan J, Sigurdsson A. Poor awareness of symptoms of oesophageal cancer. Interact Cardiovasc Thorac Surg. 2011 Jan;12(1):32-4.

15. Burford G, Bodeker G, Kabatesi D, Gemmill B, Rukangira E (2000) Traditional Medicine and HIV/AIDS in Africa. Journal of Alternative and Complementary Medicine 6(5):457-71.

16. Bakeera SK, Wamala SP, Galea S, State A, Peterson S, Pariyo GW (2009) Community perceptions and factors influencing utilization of health services in Uganda. Int J Equity Health. 14;8:25.

17. Ahmed NU, Alam MM, Sultana F, Sayeed SN, Pressman AM, Powers MB (2006) Reaching the unreachable: barriers of the poorest to accessing NGO healthcare services in Bangladesh. J Health Popul Nutr. 24(4):456-66. 